\title{
Teachers' Motivation in the Maldives - Vital but Context-Specific
}

\author{
Abdul Raheem Hasan and Lex McDonald
}

\begin{abstract}
This paper explores stakeholders' perceptions of the motivational influences for successful indigenous teachers to stay on as teachers in the islands of the Maldives. The research employs qualitative methods of interviewing, focus-group meetings and questionnaires to collect data from local indigenous groups that included school principals, leading teachers, successful teachers, parents and students. Analysis of data indicates that the participants' perceptions of what motivated successful teachers to remain as teachers are largely influenced by the cultural aspects and specific island-life characteristics. It is clear that the motivational influences to stay on in the teaching profession are contextual, inter-related, inter-dependent and multifaceted but the 'double $S$ ' of motivation - salary and status - is also evident.
\end{abstract}

Index Terms-Maldives, retention, successful teachers, teachers' motivation.

\section{INTRODUCTION}

Teachers form the largest investment in a school and can instrumentally exert the strongest direct influence on student outcomes [1]. The levels of teachers' motivation to carry out the tasks associated with teaching make a vast difference in terms of student achievements, thereby attracting other teachers, students, and parents to the school [2]. Accordingly, schools are as good as their teachers and "at their best, they tap into the hopes and talents of young people and help them grow into productive citizens" [3]. Hence, the sources of teachers' motivation are under continuous scrutiny as the sustenance of motivation at a high level is imperative for schools to enhance student achievement [4].

\section{LITERATURE REVIEW}

\section{A. Conceptual Framework}

Motivation is an elusive concept that is suffering from a lack of clarity and consensus, not only in terms of definitions, but also in understanding [5] - no definition of motivation has gained universal acceptance. While Conroy [6] defined motivation as "a person's active participation in and commitment to achieve the prescribed results" (p. 50) and, Robbins [7] noted it as "the willingness to exert high levels of effort towards organisational goals, conditioned by the

Manuscript received December 15, 2013; revised February 26, 2014. This work was supported by Victoria University of Wellington. The authors would like to acknowledge the contribution of Dr. Anne Hynds, Senior Lecturer, in this research.

Abdul Raheem Hasan is with the Victoria University of Wellington (e-mail: abdul.Hasan@vuw.ac.nz).

Lex McDonald is with the School of Educational Psychology and Pedagogy, Faculty of Education, Victoria University of Wellington (e-mail lex.mcdonald@vuw.ac.nz). effort's ability to satisfy some individual needs" (p. 355). Santrock [8] explained it as the "processes that energize, direct and sustain behaviour" (p. 414). In general terms therefore, motivation can be referred to as the forces that make someone act or not act. Therefore, for the purpose of this discussion, teachers' motivation is assumed to be the forces that energize successful teachers to join and remain in the teaching profession.

\section{B. Theoretical Perspectives}

Many researchers have considered why and how people become motivated. A number of commentators and researchers have developed theories which have now been regarded as time-tested and accepted as seminal. Some of these, particularly the hierarchy of needs theory of Maslow [9], Hertzberg's [10] two-factor theory, the theories of $x$ and $y$ of McGregor [11], [12], and Ouchi's [13] theory $z$ of motivation, and the self-determination theory (SDT) of Deci and Ryan [14] informed this research.

Many motivation theories postulated needs as prime motivators, even though Herzberg preferred to call some of them motivators and others hygiene factors. Maslow arranged the needs in a hierarchy of five levels indicating that the unmet needs, often at a higher level in the hierarchy, would be the motivator. Given the diversity of people, McGregor proposed two theories based on two sets of opposing assumptions that described the psychological status of the person to indicate what might motivate people. Ouchi's theory could be summarised as one that assumed the factors that help make employees happy as motivators. Within these theoretical parameters, teachers' motivation in the Maldives, from a constructive stance with a qualitative lens, was investigated.

\section{Research on Teacher Motivation}

Research on teachers' motivation indicates that the motivational influences for teachers are dependent upon a complex array of personal, social, cultural, economic, and geographical conditions that dictate the working environment [15]-[17]. According to Wlodkowski and Ginsberg [18], "motivation is inseparable from culture" (p.17) and hence, culture influences motivational practices [19], [20]. Geographical isolation and social factors also interfere with teachers' motivational beliefs, but teacher motivation researchers do not usually consider these factors [21]. Hence, continued research in different settings is warranted to determine what contributes to teachers' motivation and enhance their inputs for better student achievements/outcomes [22].

\section{ReSEARCh SetTing}

This research was undertaken in the small island state of 
Maldives located in the Indian Ocean. These are very small islands, with no island longer than $8 \mathrm{~km}$ and only 10 larger than $2 \mathrm{~km}^{2}$ [23]. A population of nearly 350, 000 Maldivians are scattered on 196 of approximately 1190 islands that stretch north to south across the equator [24]. The greatest population density is on Male'- the nation's capital [25], which is an island just about $1.8 \mathrm{~km}$ in length that harbours almost one-third of the total population [26]. The majority of the islands have fewer than 750 people, the lowest population on one single island being 55 [27]. The people in the Maldives are Muslim and have been so for almost 900 years [28]. It is different both religiously and culturally from its geographically closest neighbours, Sri Lanka and India [29].

Given the geographic conditions of the Maldives, where the population is dispersed on tiny islands and most islands have too small a population to justify profitable economic activities, only a handful of people are permanently employed by another person and/or companies. The central government is the major employer [27]. Hence, job opportunities are scarce and a high demand prevails for the few jobs available. It is expected that the nature of the role of the teacher is impacted upon by these physical, social, economic, and political features.

However, a further important feature to acknowledge is that the Maldives has never achieved self-sufficiency in training and retaining teachers, even though teaching is one of the main areas in which jobs on most of these small islands are available. Fig. 1 provided below shows the numbers of local and expatriate teachers during a period of over a decade from 2002 to 2012 indicating the deficiency of trained teachers. Severe shortages of trained teachers; particularly of trained local teachers have existed ever since the introduction of English-medium education over half a century ago. The country is heavily dependent on untrained local teachers and qualified expatriate teachers.

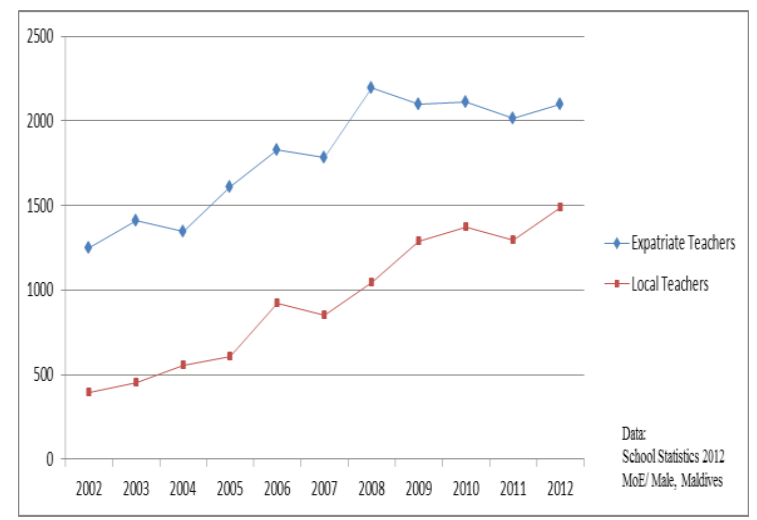

Fig. 1. Number of qualified or trained teachers in secondary schools 2002-2012

\section{Methodology}

For qualitative research there are no statistical grounds for guidance to determine the number of participants but it tends to be small [30], [31]. Hence, the number of participants for this study was purpose-determined in light of practical logistical constraints [30]). Purposive sampling techniques were employed [32]-[34]. The intention was to select participants who could use first-hand experience and were information rich to contribute to the issue under exploration
[34], [35].

Three different advisory committee meetings in three sub-cases attended by school principals, students, the representatives from parent-teacher associations, and school boards helped to identify locally accepted successful teachers. Ten such teachers, three principals, three leading teachers, five parents, six students and five policy level officials from the central Education Ministry contributed data to this research through questionnaires and individual interviews or in focus-group meetings. In total, 29 individual interviews from participants and transcripts of three focus-group meetings were analysed to derive the reported impressions.

To ensure participants' anonymity, pseudonyms were used and this research was conducted with prior approval of the VUW Faculty of Education Ethics Committee.

\section{FINDINGS}

Analysis of data indicated that a dynamic interplay of factors contributed to the understanding of what motivated local teachers to remain in the teaching profession in the Maldives. Overall, however, it was revealed that the participants' perceptions of what motivated successful teachers to remain as teachers were largely influenced by the cultural aspects and specific island-life characteristics. It was clear that the motivational influences to stay on in the teaching profession were contextual, inter-related, inter-dependent and multifaceted while the 'double $S$ ' of motivation - salary and status - was also evident.

An important dimension of motivational influences was the island-life characteristics for teachers. Within the island-life characteristics, three major themes were identified as motivational influences for teachers.

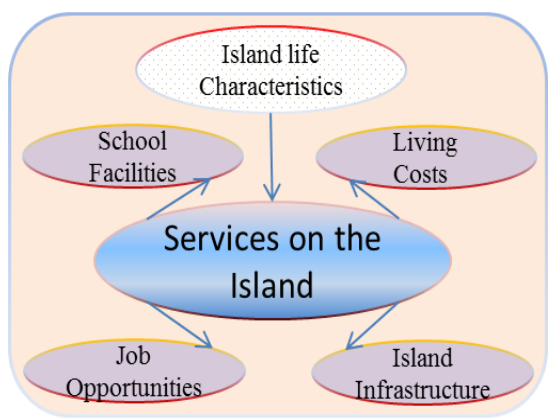

Fig. 2. The services available on the island perceived as motivational influences.

One of them was the services available on the island which is diagrammatically represented in Fig. 2 above. The other two were the professional development opportunities and and the island community expectations on teachers. This paper is based on the aspect of services available on the island as motivational influences for teachers.

\section{A. Services on the Islands}

Newly graduated teachers from the only university's Faculty of Education have a chance to tell the Ministry of Education their preferences before they are posted to a school. Often, most of their first choices happen to be their home island, particularly if they have got their extended family living there. Otherwise, it would be Male' or any other island 
that has better communication and services:

That is the perception that we have, because in the last three years that we have been at the Ministry I am finding that teachers who come from an outer island, unless they are really grounded, meaning that they have family and they have started to have children etc. their first preference, a number of the younger single people have said that the first preference would be Male'. So if we could match their preference they do have a tendency of at least taking to the job otherwise you would know that there are a number of teachers whom we could not bring although they are training who we couldn't bring them to serve. So that is there.

Ameena, MoE official

Teachers may also choose schools where there is someone they know or they are familiar with through their teaching practice or by some other means. If their preferences are not met, a number of them even refuse to take up the teaching job. Instead, they may prefer jobs in other areas even though they are qualified as teachers.

The reasons why Male' became their first preference varied. Adam, for example, indicated that the services available in the community greatly influenced teachers' motivation to be on the island when he was asked to elaborate on the motivational influences for teachers:

The facilities and services available in the community, the safety in the environment, the cooperation from people and the advancement received from the profession, the help from the leaders and their caring and cooperation, the trust and friendliness they offer are also included.

Adam, Leading Teacher

Male' is the economic hub and the nerve-centre of communications and services in the country. So this could have been one of the major reasons for their preference for Male'. It was observed that some teachers left certain schools (islands) because of the lack of facilities and services available on the island:

Most of the teachers leave the island because there are no facilities available in this island.

\section{Janna, Student}

Janna, a year 9 student, experienced difficulties in catching up with her studies when teachers frequently changed due to their leaving the island to go to places with better facilities. She was referring to facilities like healthcare, education, banking, inter-island transportation, and other island infrastructure.

Such facilities were available on islands with larger populations or located in the more established atoll capitals. Atoll capitals with more facilities seem to have attracted people, including teachers, as they become more liveable islands:

Specifically I can say this is the capital of this atoll. And because of that we have more facilities than in other islands in the atoll.

And we are fastly developing our island. So there are many facilities and the people actually want to live in this island. Those who actually need live in the island, I think; it is again another motivational factor for those teachers.
Another thing is that most of these teachers are actually going to Male' but now it is very crowded and (eheheh) it is very difficult for them to live in Male'. So they are forced to go back to their home place (ehehehe).

Yes, all the people, all the people that I have met they are very happy to came back from Male' and they said that it is actually a horrible place to be in Male' and they have faced very very terrible experience in Male' so they couldn't tolerate it and so they came back and they are happy.

Nazeem, School Head

\section{B. Island Infrastructure}

Male' is the island that has the best of almost all services and the services available on a particular island were seen to attract people or distract people from that island. Teachers were also seen to be moved to follow this trend. One of the participants commented on this issue as:

There are many facilities that we cannot get unless we go to Male' but nowadays it is changed. Like a hospital is there in regional level and the post office is there and banking service is there established and so many other services are there and many things actually are cheaper compared to Male'.

Nazeem, School Head

As indicated by Nazeem, the cost of living is also a factor in retaining teachers in a particular school. This also has a bearing on the opportunities for jobs and/or to earn income.

\section{Living Costs}

Cost of living is also an important factor that the participants have considered as having an influence on teachers' motivation to stay on in teaching on a particular island. It is considerably impacted by the kind of island and the type of community on the island. Often the developed islands have a higher cost of living. Development also impacts on the way of life and brings changes to the way of life. For example, a materialistic orientation develops and individuals want to make money from their activities. Hence, many commodities (e.g., fish, coconuts) that were available free on the island become costly items.

Fish and coconuts used in many foods were, until very recently, available on many islands free of charge. Fishing was often a pastime on the beaches and coconuts picked from the bush. A coconut taken from the bush could be kept on the ground with a circle around denoting ownership. It could remain there until the person retrieves it or until the circle was erased with the rain or in some other way.

On some islands there have also been communal fishing and communal coconut picking until 30 to 40 years ago. They would distribute the fish or coconuts among the people on the island irrespective of participation but most would participate.

These island customs have however changed somewhat presumably related to modern development and as indicated, with development people begin to become more materialistic - they want money and possessions. This makes the general living costlier.

\section{Job Opportunities}

Since the islands are small there are very few opportunities for jobs and on most islands the government is the biggest 
employer. On the whole, the government is the largest employer and the education sector employs many. Therefore, the education sector is thought to have guaranteed job opportunities as there is a shortage of applicants for positions (in which many expatriates are employed). Consequently, teaching is seen as a viable attractive option for many seeking employment. Being a civil service position, it is almost guaranteed for life providing adequate performance is maintained. So, reasonably easy access to the profession and job security afterwards draw people to the teaching profession:

The interest may be created due to the fact that ... one can stay on for a long time if the person is able to perform satisfactorily.

Fikry, Parent

\section{E. School Facilities}

The facilities available in the school are perceived to be an attraction for teachers to work in the school and accordingly often will motivate teachers to remain in that school:

The other thing that motivates teachers is the facilities for teaching. Availability of facilities plays an important role. Teachers are very creative people. They find it difficult to make the students benefit out of their creativity when they do not have the resources they require.

For example, modern technology, ICT, IT are lacking in schools. This hinders teachers' motivation. So, I believe that the availability of these resources and facilities will increase teachers' motivation.

Shafraaz, Leading Teacher

A teacher-parent also highlighted the desire to be able to use technology to improve their teaching, indicating that it would motivate teachers:

If computer laptops are given, they will also save time for the teachers and it will be easier for them to make worksheets and surf the net for more information if there is internet access. So this will motivate teachers.

\section{Abbas, Teacher/Parent}

Another parent reiterated the importance of school facilities being related to teachers' motivation to remain and increase their efficiency in performing their roles:

The best thing the management can do is to make the school environment an easy place to work in, have the facilities for teaching readily available, and have the network by which all can access modern facilities. When the management modernises the school facilities teachers will be motivated. For example, the installation of smart boards also increased motivation. Teachers can come with their own pendrives and share many facilities with children in a short period of time.

Fikry, Parent

Both a leading teacher and a school head in separate interviews also highlighted the importance of an appropriate working environment and a convenient place for teachers to work as a strong motivational influence:

So, an atmosphere appropriate for work is the most important thing.
Adam, Leading Teacher

A place where they can work conveniently and with some modern facilities; well-equipped school I think they need because now it's very er... what we call er... it depends on technology. So I think we have to develop the technologies, the facilities in our school to motivate those teachers even.

More facilities, like er..., there are so many things that the teachers need for teaching like teaching materials they may need...

And the printing materials and some other materials like even now we are giving them internet access freely. All the teachers are getting internet access freely. And recently we have [provide] wifi point[s] and with their own laptop[s] also they can access the internet and the school server also, so they can work very easily. So that type of arrangement we are always trying to give them these sorts of services to motivate them.

Nazeem, School Head

When Nazeem stated "a place where they can work conveniently", he was also referring to the school building and compound. He was indicating that the facilities such as school hall, staff room, type of classrooms and the space to conduct extra-curricular activities have bearings upon teachers' motivation:

When teachers come here, there is actually no working place for them. Even the staffroom is very congested due to the size of it. And there are no proper classrooms here. It is open plan.

So, since we are having double session schools, students are using the classroom twice so they don't have the freedom of showing their displays in the classrooms and they are not, our teachers don't get the chance to conduct extra activities for students even because we don't have a hall even here. There are so many other resources that we can build in the school to motivate those teachers.

Nazeem, School Head

Hence, the physical infrastructure of the school was observed to play a role in teachers' motivation:

Physical infrastructure of the school also contributes to teachers' motivation. The development of staff room and supervisor's room in 2008 also brought about a noticeable change in the teachers.

Shafraaz, Leading Teacher

Even the basic facilities like the toilets and sick-rooms were observed to be playing a role in motivating or de-motivating teachers:

This school where we don't have even a sick room, we don't have a counsellor, [and] we don't have anything, not even toilets, still with 74 teachers with only one damaged toilet. That is too much for a school like this, 74 teachers and only one toilet.

So most of the time we had to go back home if you want to go to the toilet. Those are some of the facilities where (ehehe) teachers are really de-motivated.

Shafu, Leading Teacher

Lack of services was considered a hardship and teachers considered they were unable to perform their duties. A parent 
also noted the importance of facilities likes toilets, cafeterias and changing rooms for teachers as motivational influences:

The management can provide better toilet facilities where they can wash and refresh or change clothes. They can also provide opportunities for teachers to play and have refreshments in the school.

If the school has all these facilities it becomes a world of their own and teachers of other schools will envy the teachers of such a school.

Fikry, Parent

Furthermore, effective and timely provision of services along with a cooperative orientation to meet teachers' needs was perceived to be a binding force that kept the teachers in the school:

It is important to provide good services from the school and cooperation from all concerned parties to avoid them leaving the school.

Adam, Leading Teacher

Even the cleaners were observed playing a role in sustaining the motivation of the teachers by offering effective and timely services maintaining clean and orderly school premises:

The cleaners also can help teachers by keeping the place nice and tidy. These are motivational factors.

Hazlaan, School Principal

Likewise, all the members of the auxiliary staff of the school also make impact through their services. Among the services, the opportunity the teachers have for their social and personal development to exploit their creativity was also seen to be an important motivational influence.

\section{DISCUSSION AND IMPLICATIONS}

The findings of this study were generally consistent with the lower level needs of Maslow's hierarchy [9] and the participants of this study highlighted some of Herzberg's [10] hygiene factors as motivational influences for teachers in the Maldives. Such factors were observed to provide proper conducive conditions stipulated in theory Y [11] to sustain motivation for teachers to fulfil their teaching and related responsibilities autonomously [14] in a happy environment on the islands as suggested by Ouchi as a requisite to sustain motivation. Klassen et al [21] idea to consider physical and geographical conditions while exploring teacher motivation also seemed a very plausible idea. The complexity of teacher motivation and its inter-dependency upon a complex array of personal, social, cultural, economic, and political conditions that govern the situations in which teachers function were largely supported by these findings [16], [36].

These findings have specific implications for the Maldivians who, for a long time have lived in a remote isolated island situation and until relatively recently the islands were essentially unknown to the wider world. They have managed their affairs by themselves internally and externally. Therefore, the available local resources within the islands have been found to be motivational influences for teachers to remain as teachers. The island development initiatives may result in enhancing teachers' desire to stay on as teachers on particular islands.

\section{LIMITATIONS AND DELIMITATIONS}

The scope of this study was limited to the perceptions of the indigenous stakeholders' views about what motivates successful local teachers to continue in the role. Future research could include foreign teachers' perceptions to create a wider spectrum for a fuller understanding of the motivational influences for the teachers to stay in these uniquely vulnerable islands.

\section{CONCLUSION}

Motivational influences for successful teachers to remain as teachers on the remote and isolated islands were found to be highly contextual, inter-related, inter-dependent and multifaceted. Among them, this research has highlighted the island-life characteristics as perceived by various stakeholders as important motivational influences for teachers. However, in any society changes occur and this dynamic interplay could readily be disrupted particularly as modern life intervenes. Hence, on-going research is needed to continually evaluate what motivates teachers to persist as being teachers [37].

\section{ACKNOWLEDGMENT}

The contribution of Dr. Anne Hynds in conducting this research is acknowledged with gratitude. Her comments and suggestions have improved the research and its outcomes immensely. The authors are extremely grateful to her.

\section{REFERENCES}

[1] E. A. Hanushek, "The economic value of higher teacher quality," Economics of Education Review, vol. 30, no. 3, pp. 466-479, 2011.

[2] S. Hayden. (2011). Teacher motivation and student achievement in middle school students. ProQuest Dissertations and Thesis. [Online]. Available:

http://udini.proquest.com/view/teacher-motivation-and-student-pqid:2 556274561/

[3] B. Ki-moon. (October 2012). Message on World Teachers Day. [Online]. Available: http://www.unis.unvienna.org/unis/en/pressrels/2012/unissgsm377.ht $\mathrm{ml}$

[4] R. Ruthankoon and S. O. Ogunlana, "Testing Herzberg's two-factor theory in the Thai construction industry," Engineering, Construction and Architectural Management, vol. 10, pp. 333-341, 2003.

[5] C. Rhodes, "Book review: The motivation and retention of teachers," Educational Management Administration and Leadership, vol. 34, pp. 433-434, 2006.

[6] W. J. Conroy, "Motivating workers to follow leaders," Iron Age New Steel, vol. 10, pp. 50-51, 1994.

[7] S. P. Robbins, Organisational Behaviour: Concepts, Controversies, Applications, 8th ed., New Jersey, Prentice Hall, 1998.

[8] J. W. Santrock, Educational Psychology, 2nd ed., New York, McGraw-Hill, 2004.

[9] A. H. Maslow, Motivation and Personality, New York: Harper \& Row, Publishers, 1954.

[10] F. Herzberg, Work and the Nature of Man, New York: The World Publishing Company, 1966.

[11] D. M. McGregor, "Adventure in thought and action," in Fifth Anniversary Convocation of the School of Industrial Management, Cambridge, April, 1957.

[12] D. M. McGregor, The human Side of Enterprise (Annotated Edition), New York: McGraw-Hill, 2006. 
[13] W. G. Ouchi, Theory: How American Business can Meet the Japanese Challenge, Reading, Massachusetts: Addison-Wesley Publishing Company, 1981.

[14] E. L. Deci and R. M. Ryan, Intrinsic Motivation and Self-Determination in Human Behaviour, New York, Plenum, 1985.

[15] D. Donelson, "Should you bribe or bully your team?" [Commentary], LP-Gas, vol. 65, pp. 48-52, 2005.

[16] A. Hynds and L. McDonald, "Motivating teachers to improve learning for culturally diverse students in New Zealand: promoting Māori and pacific islands student achievement," Professional Development in Education, vol. 36, pp. 525-554, 2010.

[17] UNESCO, The Dakar Framework for Action, in World Education Forum, Dakar, Senegal, 26-28 April, 2000.

[18] R. J. Wlodkowski and M. B. Ginsberg, "A framework for culturally responsive teaching," Educational Leadership, vol. 53, pp. 17-21, 1995.

[19] S. R. Crow, "Relationships that foster intrinsic motivation for information seeking," School Libraries Worldwide, vol. 15, no. 2, pp. 91-112, 2009.

[20] S. Helou and T. Viitala. (2007). How culture and motivation interacts? A cross-cultural study. Master thesis. [Online]. Available: http://umu.diva-portal.org/smash/record.jsf?pid=diva2:140469

[21] R. M. Klassen, R. Y. Foster, S. Rajani, and C. Bowman, "Teaching in the Yukon: Exploring teachers' efficacy beliefs, stress, and job satisfaction in a remote setting," International Journal of Educational Research, vol. 48, pp. 381-394, 2010.

[22] C. Schepers, S. D. Gieter, R. Pepermans, C. D. Bois, R. Caers, and M. Jegers, "How are employees of the nonprofit sector motivated? A research need," Nonprofit Management and Leadership, vol. 16, pp. 191-207, 2005.

[23] E. Gischler, "Sedimentation on Rasdhoo and Ari Atolls, Maldives, Indian Ocean," International Journal of Paleontology, Sedimentology and Geology, vol. 52, no. 3, pp. 341-360, 2006.

[24] MPND. (2006). Census Analysis. [Online]. Available: http://planning.gov.mv/en/images/stories/publications/analysiscd/pdf/ 2.pdf

[25] MPND, Maldives at a Glance, Male, November 2008.

[26] M. Aboobakur, A. Latheef, A. J. Mohamed, S. Moosa, R. M. Pandey, A. Krishnan et al., "Surveillance for non-communicable disease risk factors in Maldives: Results from the first STEPS survey in Male',' International Journal of Public Health, vol. 55, pp. 489-496, October 2010.

[27] MPND, Seventh National Development Plan 2006-2010: Creating New Opportunities, Male, 2007.

[28] R. A. Ahmed, "The state and national foundation in the Maldives," Cultural Dynamics, vol. 13, pp. 293-315, 2001.
[29] C. Maloney, "The Maldives: New stresses in an old nation," Asian Survey, vol. 16, pp. 654-671, 1976.

[30] M. B. Miles and M. A. Huberman, Qualitative Data Analysis: A Sourcebook of New Methods, Beverly Hills: Sage Publications, 1984.

[31] K. F. Punch, Introduction to Social Research Quantitative and Qualitative Approaches, 2nd ed., London: SAGE Publications Ltd., 2005, pp. 55.

[32] E. Babbie, The Practice of Social Research, 13 ed., Belmont: Wadsworth, Cengage Learning, 2013, pp.190.

[33] I. T. Coyne, "Sampling in qualitative research: Purposeful and theoretical sampling; merging or clear boundaries?" Journal of Advanced Nursing, vol. 26, pp. 623-630, 1997, pp. 627.

[34] M. Patton, Qualitative Evaluations and Research Methods, Beverly Hills, Sage, pp. 169-186, 1990.

[35] J. W. Creswell, Educational Research Planning, Conducting, and Evaluating Quantitative and Qualitative Research, Upper Saddle River: Pearson, 2008.

[36] A. R. Hasan and A. Hynds. (2013). Cultural Influence on Teacher Motivation - A Country Study of Maldives. International Journal of Social Science and Humanity. [Online]. 1(4). pp. 19-28. Available: http://search.proquest.com/docview/1441427284/142A6D5B7A079C 204B $9 / 5$ ? accountid $=14782$

[37] M. Zembylas and E. Papanastasiou, "Job satisfaction among school teachers in Cyprus," Journal of Educational Administration, vol. 42, pp. 357-374, 2004

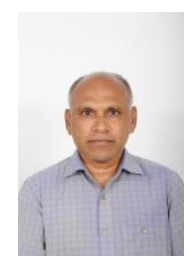

Abdul Raheem Hasan is a PhD student in the School of Educational Psychology and Pedagogy, Faculty of Education at Victoria University of Wellington. His thesis is on teacher motivation. Abdul Raheem has been in public service in the capacities of a teacher, school principal as educational administrator etc. He was the director general of the human resource Department of Ministry of Education of Maldives when he embarked on his $\mathrm{PhD}$ project to do research on teacher motivation.

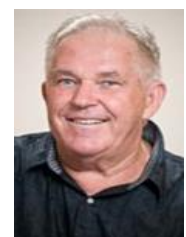

Lex McDonald is a $\mathrm{PhD}$ and the associate dean (academic) in the Faculty of Education at Victoria University of Wellington. He has been a teacher, adviser and educational psychologist working and living in New Zealand, the UK, Cook Islands and Samoa. He has explored educational issues in the small island states and in particular researched the importance of culture in determining educational processes as it relates to training and professional development of teachers. 